\title{
Feasibility of laparoscopic liver resection for liver cavernous hemangioma: A single-institutional comparative study
}

\author{
Younghuen Shin, Jinsoo Rhu, Gyu-Seong Choi, Jong Man Kim, Jae-Won Joh, and Choon Hyuck David Kwon
}

\author{
Department of Surgery, Samsung Medical Center, Sungkyunkwan University School of Medicine, Seoul, Korea
}

\begin{abstract}
Backgrounds/Aims: While minimal invasive surgery has become popular, the feasibility of laparoscopy for liver cavernous hemangioma has not been shown. Methods: Patients who underwent hepatectomy for liver cavernous hemangioma from January 2008 to February 2019 at the Samsung Medical Center were reviewed. Patients who underwent trisectionectomy were excluded. Background characteristics, along with operative and postoperative recovery, were compared between the laparoscopy and open surgery groups. Results: Forty-three patients in the laparoscopy group and 33 patients in the open surgery group were compared. The differences in the background characteristics were presence of symptoms $(14.6 \%$ in laparoscopy vs. $57.1 \%$ in open, $p<0.001)$ and tumor location (right, left and both side $p=0.017)$. The laparoscopy group had smaller blood loss $(p=0.001)$, lesser blood transfusion requirements $(p=0.035)$, lower level of post-operative total bilirubin, prothrombin time (INR) $(p=0.001,0.003$ each), shorter hospital stay $(p=0.001)$, earlier soft diet start $(p<0.001)$, earlier drain removal $(p<0.001)$ and shorter amount and duration of additional pain control ( $p=0.001, p=0.017$ each). There was no significant difference in complication after surgery between two groups $(p=0.721)$. All the patients showed pathologic report of benign hemangioma regardless of type of surgery $(100 \%)$. Almost every patients reported no symptom or relief of symptom in both groups $(97.7 \%, 93.9 \%$ each). Conclusions: Laparoscopic liver resection for liver cavernous hemangioma can be safely performed with improved postoperative recovery. However, surgery for liver cavernous hemangioma should be conducted with informed consent of the patients. (Ann Hepatobiliary Pancreat Surg 2020;24:137-143)
\end{abstract}

Key Words: Hemangioma; Laparoscopy; Laparoscopic liver resection; Cavernous hemangioma

\section{INTRODUCTION}

Laparoscopic liver resection is now performed widely throughout the world, especially for liver malignancies such as hepatocellular carcinoma and colorectal liver metastasis. $^{1-5}$ Studies that compared the feasibility of laparoscopic liver resection showed that, in general, laparoscopy may be superior to open surgery in blood loss and postoperative recovery despite the longer operation time., ${ }^{2,6-9}$ Although laparoscopic liver resection is one of the most interesting topics in the field of hepatic surgery, the feasibility of laparoscopic liver resection has focused on liver malignancies.

LCH is a female-dominant benign tumor with a prevalence of 0.5 to $7.3 \%$ in the general population. ${ }^{10,11}$ Most $\mathrm{LCH}$ does not require surgical resection, but surgery can be considered for patients who exhibit tumor-related symptoms, show an increase in tumor size, or whose diagnosis cannot exclude malignancy. Since there is no absolute surgical indication for LCH, surgery for LCH is usually associated with large tumor size and a risk of bleeding. Although there have been reports of laparoscopy for $\mathrm{LCH},{ }^{12-14}$ there are limited systematic studies reporting the feasibility of laparoscopy for $\mathrm{LCH}^{15}$ This is because various treatment modalities, such as radiofrequency ablation or transcatheter arterial embolization, can be performed for $\mathrm{LCH}^{16-18}$ However, certain LCHs can only be treated with surgical resection. Therefore, we designed this study to analyze the feasibility of laparoscopy for LCH.

Received: August 21, 2019; Revised: January 25, 2020; Accepted: January 29, 2020

Corresponding author: Gyu-Seong Choi

Department of Surgery, Samsung Medical Center, Sungkyunkwan University School of Medicine, 81 Irwon-ro, Gangnam-gu, Seoul 06351, Korea Tel: +82-2-3410-0414, Fax: +82-2-3410-0040, E-mail: med9370@gmail.com

Copyright (C) 2020 by The Korean Association of Hepato-Biliary-Pancreatic Surgery

This is an Open Access article distributed under the terms of the Creative Commons Attribution Non-Commercial License (http://creativecommons.org/ icenses/by-nc/4.0) which permits unrestricted non-commercial use, distribution, and reproduction in any medium, provided the original work is properly cited. Annals of Hepato-Biliary-Pancreatic Surgery • pISSN: 2508-5778 - eISSN: 2508-5859 


\section{MATERIALS AND METHODS}

\section{Patients and data}

Patients who underwent liver resection for $\mathrm{LCH}$ from January 2008 to February 2019 at the Samsung Medical Center were retrospectively reviewed for study inclusion. Patient demographic data were collected along with past medical histories and their estimated American Society of Anesthesiologists (ASA) score. Pre- and postoperative laboratory data were collected along with the location and size of the LCH. Surgical approach and extent of resection were also reviewed. Operative data, specifically operation time, estimated blood loss during surgery, and rate of transfusion, were collected. For postoperative recovery, we reviewed the time between operation and discharge, the day a soft diet was initiated, when complete removal of drainage catheters occurred, the amount of additional opioids required (in addition to analgesics provided per protocol), and the last day that additional opioids were administered. Patients were under patient-controlled anesthetics, which is based on fentanyl. No additional analgesics were prescribed unless the patient requested them for pain control. Postoperative complications were reviewed, and the severity of complications were categorized based on the Clavien-Dindo Classification. $^{19}$

\section{Statistical analysis}

To minimize selection biases that can interfere with statistical analyses, surgeries that were never performed by laparoscopy and only by open surgery, such as trisectionectomy, during the period were excluded from the analysis. Cases with open conversion were included in the laparoscopic group according to principle of intention to treat. Comparisons of baseline characteristics and operative and postoperative recovery were conducted using a t-test and Mann-Whitney test for numerical variables. A Pearson's chi-square test, Fisher's exact test, and linear-by-linear association were performed for categorical variables. For the analysis, certain variables were re-categorized. ASA score was categorized into class I and class II/III. The location of LCH was categorized into right, left, and both sides. Tumor number was categorized into single or multiple tumors. Surgical extent was compared after re-categorizing into less than four segments or four or more segments. The severity of complications was compared after re-categorizing into no complications, class I/II complications, and class III/IV/V complications. Numerical variables with normal distributions were presented as the mean \pm standard deviation (SD), while variables that did not show normal distributions were presented as the median and interquartile range (IQR). Statistical significance was indicated as a two-tailed $p$-value of $<0.05$. All statistical analyses were performed using SPSS 20.0 (SPSS Inc., Chicago, IL). This study was approved by the Institutional Review Board of the Samsung Medical Center (IRB No. 2018-07-157).

\section{RESULTS}

During the applicable study period, a total of 84 patients underwent liver resection for $\mathrm{LCH}$. While 43 patients underwent laparoscopic liver resection, 41 patients underwent open liver resection. Among those patients who underwent open liver resection, eight patients underwent open trisectionectomy $(18.6 \%)$ and were excluded from our study (Table 1).

\section{Comparison of baseline characteristics}

Forty-three patients in the laparoscopy group and 33 patients in the open surgery group were compared (Table 2). The differences in the background characteristics were indication for surgery $(p<0.001)$, preoperative albumin level $(p=0.020)$ and tumor location (Rt, both, Lt $p=0.017)$. While six patients $(14.6 \%)$ in the laparoscopy group reported symptoms prior to operation, over than half of the patients in the open surgery group $(n=20,57.1 \%)$ reported symptoms. In regard of tumor location, in the laparo-

Table 1. Surgical resections performed from January 2008 to February 2019 for liver cavernous hemangioma

\begin{tabular}{lccl}
\hline & $\begin{array}{c}\text { Laparoscopy } \\
(\mathrm{n}=41)\end{array}$ & $\begin{array}{c}\text { Open } \\
(\mathrm{n}=43)\end{array}$ \\
\hline Subsegmentectomy & $4(9.8 \%)$ & 2 & $(4.7 \%)$ \\
Segmentectomy & $4(9.8 \%)$ & 2 & $(4.7 \%)$ \\
Sectionectomy & $11(26.8 \%)$ & 6 & $(14.0 \%)$ \\
Central hepatectomy-3 segments & $1(2.4 \%)$ & 1 & $(2.3 \%)$ \\
Central hepatectomy-4 segments & $0(0 \%)$ & $1(2.3 \%)$ \\
Hemihepatectomy & $18(43.9 \%)$ & $14(32.6 \%)$ \\
Extended hemihepatectomy & $3(7.3 \%)$ & $9(20.9 \%)$ \\
Trisectionectomy & - & $8(18.6 \%)$ \\
\hline
\end{tabular}


Table 2. Comparison of the background characteristics between the laparoscopy group and open surgery group

\begin{tabular}{|c|c|c|c|}
\hline Variables & $\begin{array}{l}\text { Laparoscopy } \\
(\mathrm{n}=43)\end{array}$ & $\begin{array}{l}\text { Open } \\
(n=33)\end{array}$ & $p$-value \\
\hline $\operatorname{Sex}(M / F)$ & $7 / 36$ & $12 / 21$ & 0.062 \\
\hline Age, mean \pm SD (years) & $46.4 \pm 10.3$ & $50.6 \pm 11.2$ & 0.095 \\
\hline Body mass index, mean \pm SD $\left(\mathrm{kg} / \mathrm{m}^{2}\right)$ & $22.7 \pm 3.6$ & $22.3 \pm 3.0$ & 0.445 \\
\hline Indication for surgery (Symptom vs. other) & & & $<0.001$ \\
\hline Symptom & $6(14.6 \%)$ & $20(57.1 \%)$ & \\
\hline Increase in size & $32(78.0 \%)$ & $10(28.6 \%)$ & \\
\hline Possibility of malignancy & $3(7.3 \%)$ & $5(14.3 \%)$ & \\
\hline ASA score & & & 0.664 \\
\hline Class I & $24(58.5 \%)$ & $18(51.4 \%)$ & \\
\hline Class II/III & $17(41.5 \%)$ & $17(48.6 \%)$ & \\
\hline Major operation of upper abdomen (\%) & $3(7.3 \%)$ & $1(2.9 \%)$ & 0.231 \\
\hline \multicolumn{4}{|l|}{ Preoperative test } \\
\hline Hemoglobin, median (g/dl Q1-Q3) & $12.6(11.8-13.3)$ & $12.8(11.7-14.5)$ & 0.438 \\
\hline Platelet, median $\left(\times 10^{3} / \mu \mathrm{l}\right)$ & $215.0(167.0-249.0)$ & $199.0(140.5-227.5)$ & 0.130 \\
\hline Albumin, median (g/dl) & $4.5(4.3-4.7)$ & $4.2(4.1-4.6)$ & 0.020 \\
\hline Total bilirubin, median (mg/dl) & $0.6(0.3-0.8)$ & $0.7(0.5-1.3)$ & 0.073 \\
\hline Aspartate aminotransferase, median (U/L) & $18.0(14.0-21.0)$ & $21.0(17.0-24.0)$ & 0.059 \\
\hline Alanine aminotransferase, median (U/L) & $13.0(10.0-20.0)$ & $16.0(11.0-23.0)$ & 0.339 \\
\hline Prothrombin time, INR, median (U/L) & $1.00(0.95-1.05)$ & $1.02(0.99-1.10)$ & 0.079 \\
\hline \multicolumn{4}{|l|}{ Pathologic data } \\
\hline Location & & & 0.017 \\
\hline Right side & $14(32.5 \%)$ & $21(63.6 \%)$ & \\
\hline Both & $3(7.0 \%)$ & $2(6.1 \%)$ & \\
\hline Left side & $26(60.5 \%)$ & $10(30.3 \%)$ & \\
\hline Number of tumors & & & 0.778 \\
\hline Single $(\%)$ & $33(76.7 \%)$ & $27(81.8 \%)$ & \\
\hline Multiple (\%) & $10(23.3 \%)$ & $6(18.2 \%)$ & \\
\hline Size, median (cm Q1-Q3) & $10.5(6.2-14.0)$ & $9.5(6.9-14.8)$ & 0.769 \\
\hline Surgical extent & & & 0.101 \\
\hline Less than 4 segments & $22(51.1 \%)$ & $10(30.3 \%)$ & \\
\hline 4 segments or more & $21(48.9 \%)$ & $23(69.7 \%)$ & \\
\hline
\end{tabular}

ASA, american society of anesthesiologists; INR, International normalized ratio

scopic group, 14 patients had tumor on their right side of liver, 26 patients on the left side and 3 patients on both sides. On the other hand, in the open group 21 patients had tumor on their right side, 10 patients on the left side and 2 patients on the both sides. There were no differences in number $(p=0.778)$, or size $(p=0.769)$ of LCH between the two groups. There was no significant difference in the surgical extent between the two groups $(p=0.101)$.

\section{Comparison of operative and postoperative course}

Table 3 shows the comparison of operative and postoperative course between the two groups. Our study shows operation times of two groups were not significantly different $(217.6 \pm 110.6 \mathrm{~min}$ vs. $263.9 \pm 98.6 \mathrm{~min}$ $p=0.058$ ) while estimated blood loss was larger in the open surgery group as compared to the laparoscopy group (median $400 \mathrm{cc}$ vs. $300 \mathrm{cc}, p=0.001$ ). Also, open group had higher chance of transfusion during or after surgery (22.9\% vs. $2.4 \% p=0.035)$.

While postoperative peak levels of aspartate aminotransferase (AST, $p=0.374$ ), alanine aminotransferase (ALT, $p=0.579$ ) were similar between the two groups, the peak total bilirubin $(p=0.003)$ and international normalized ratio (INR) of prothrombin time (PT) was higher in the open surgery group compared to the laparoscopy group (mean 1.41 vs. $1.28, p=0.003$ ).

There were significant differences in postoperative recovery between the two groups. The hospital stay was shorter in the laparoscopy group compared to the open surgery group (median 7.0 days vs. 9.0 days $p=0.001$ ). 
Table 3. Comparison of operative and postoperative data between the laparoscopy group and open surgery group

\begin{tabular}{|c|c|c|c|}
\hline Variables & $\begin{array}{l}\text { Laparoscopy } \\
\qquad(\mathrm{n}=43)\end{array}$ & $\begin{array}{l}\text { Open } \\
(\mathrm{n}=33)\end{array}$ & $p$-value \\
\hline \multicolumn{4}{|l|}{ Operative data } \\
\hline Operation time, mean $\pm \mathrm{SD}(\min )$ & $217.0 \pm 110.6$ & $265.2 \pm 98.7$ & 0.058 \\
\hline Estimated blood loss, median (cc Q1-Q3) & $300.0(100.0-400.0)$ & $400.0(257.5-1000.0)$ & 0.001 \\
\hline Transfusion $(\%)$ & $1(2.4 \%)$ & $8(22.9 \%)$ & 0.035 \\
\hline \multicolumn{4}{|l|}{ Postoperative data } \\
\hline Total bilirubin, median (mg/dl Q1-Q3) & $1.30(0.80-1.70)$ & $1.90(1.45-2.45)$ & 0.001 \\
\hline Aspartate aminotransferase, median (U/L) & $160.0(100.0-258.0)$ & $209.0(127.0-300.5)$ & 0.374 \\
\hline Alanine aminotransferase, median $(\mathrm{U} / \mathrm{L})$ & $163.0(95.0-271.0)$ & $166.0(119.5-273.5)$ & 0.579 \\
\hline Prothrombin time, INR, mean \pm SD (U/L) & $1.28 \pm 0.18$ & $1.41 \pm 0.22$ & 0.003 \\
\hline \multicolumn{4}{|l|}{ Postoperative recovery } \\
\hline Hospital stay, median (days Q1-Q3) & $7.0(6.0-9.0)$ & $9.0(8.0-10.0)$ & 0.001 \\
\hline Starting day of soft diet, median (days) & $2.0(1.0-2.0)$ & $4.0(3.0-4.0)$ & $<0.001$ \\
\hline Removal of drainage catheter, median (days) & $4.0(3.0-5.0)$ & $5.0(5.0-7.0)$ & $<0.001$ \\
\hline Amount of additional opioid, median (times) & $1.0(0.0-3.0)$ & $3.0(2.0-6.0)$ & 0.001 \\
\hline Last day for additional opioid, median (days) & $2.0(0.0-4.0)$ & $3.0(2.0-5.0)$ & 0.017 \\
\hline Complications (\%) & $4(9.3 \%)$ & $4(12.1 \%)$ & 0.721 \\
\hline Clavien-Dindo classification & & & 0.621 \\
\hline None & $39(90.7 \%)$ & $29(87.9 \%)$ & \\
\hline $\mathrm{I} / \mathrm{II}$ & $3(7.0 \%)$ & $2(6.1 \%)$ & \\
\hline III/IV/V & $1(2.3 \%)$ & $2(6.0 \%)$ & \\
\hline \multicolumn{4}{|l|}{ Pathologic report } \\
\hline Carvernous hemangioma & $43(100 \%)$ & $33(100 \%)$ & \\
\hline Malignancy or others & $0(0 \%)$ & $0(0 \%)$ & \\
\hline Postoperative symptom evaluation & & & 0.576 \\
\hline No symptom or subsided & $42(97.7 \%)$ & $31(93.9 \%)$ & \\
\hline Symptom deteriorated or newly occurred & $1(2.3 \%)$ & $2(6.1 \%)$ & \\
\hline
\end{tabular}

INR, International normalized ratio

The laparoscopy group initiated a soft diet earlier than the open surgery group (median 2.0 days vs. 4.0 days $p<0.001)$. Drainage catheters were removed earlier in the laparoscopy group than in the open surgery group (median 4.0 days vs. 5.0 days $p<0.001)$. Patients in the laparoscopy group required less additional opioids than the open group (median 1 times vs. 3 times $p=0.001$ ). While the laparoscopy group had additional opioids for median of 2 days, the open surgery group had additional opioid for median of 3 days $(p=0.017)$. There were no differences in rate or severity of complications between the two groups. ( $p=0.721,0.621$ each). All the patients were reported with pathologic report of benign carvernous hemangioma postoperatively (100\%).

There was no significant difference in postoperative symptoms, between two groups ( $p=0.576$ ). Among 43 laparoscopic group patients, 6 patients underwent operation due to symptoms such as abdominal discomfort. Only one patient complained of abdominal discomfort in the post- operative period. On the other hand, 20 patients in 35 open group patients had preoperative symptoms which disappeared postoperatively in 19 patients. One patient who did not have symptom initially, complained newly occurred symptom in the postoperative period due to complication of surgery (biliary leakage).

\section{Patients with open conversion or postoperative complications}

There were two open conversion cases in the laparoscopy group. A 71-year-old female patient underwent open conversion during laparoscopic left lateral sectionectomy due to bleeding. There were no postoperative complications. A 43-year-old female patient underwent open conversion during laparoscopic right hemihepatectomy due to bleeding. The patient needed an additional transfusion after the operation.

There were three more patient cases with postoperative complications in laparoscopy group A 47-year-old female 
patient underwent transfusion due to postoperative bleeding after laparoscopic extended right hemihepatectomy. A 71-year-old female patient had pulmonary edema after laparoscopic right posterior sectionecetomy. The patient recovered after administering intravenous furosemide. A 61-year-old female patient underwent percutaneous drainage for complicated fluid collection that occurred after laparoscopic left lateral sectionectomy.

There were five patient cases associated with complications in the open surgery group. A 28-year-old male patient underwent percutaneous drainage for biloma that occurred after open central hepatectomy. 64-year-old female underwent reoperation for postoperative abscess formation. 33-year-old female delayed her discharge due to severe postoperative pain which required additional pain killer. Two female patients had minor wound problem after surgery which was resolved after wound dressing.

\section{Patients who underwent open trisectionectomy}

There were eight patients who underwent open trisectionectomy (Table 4). All eight patients were female. The median tumor size was $15.75 \mathrm{~cm}$ and ranged from $8 \mathrm{~cm}$ to $35 \mathrm{~cm}$. Half of the patients had a tumor on the right side $(n=4,50.0 \%)$. Median operation time was 465 minutes (range 211-607 mins). Estimated blood loss was $900 \mathrm{ml}$ (range 150-3200 ml). Half of the patients had transfusions during or after the operation. The median hospital stay was 21 days (range 8-74). The median day patients began a soft diet was day 4 (range 2-5). The drainage catheter was removed in a median of 13.5 days (range 7-74). The median number of additional opioids was 3 (range 1-15). Additional opioids were given for a median of 3 days (range 1 to 12). Six out of eight patients (75.0\%) had complications and four of them had ClavienDindo grade III complications. The two cases with grade II complications were ascites, which was controlled by diuretics, and postoperative ileus, which resolved after conservative management. Cases with grade III complications were postoperative bleeding, which required reoperation, biliary stricture, which was managed with hepaticojejunostomy, and biloma and bile leakage, which needed percutaneous drainages.

\section{DISCUSSION}

Our study demonstrated that laparoscopic liver resection, when compared to open surgery, can be performed safely for $\mathrm{LCH}$ and with better postoperative recovery.

Although the feasibility of laparoscopy in liver resection has been reported by numerous hepatic surgeons, ${ }^{2-4,7}$ there has been limited evidence on the feasibility of laparoscopy for $\mathrm{LCH}^{15}$ By comparing 31 patients with laparoscopy and 100 patients with open surgery, a report by $\mathrm{Yu}$ et al. ${ }^{15}$ showed superior recovery in spite of longer operation times. Unfortunately, the analysis was based on different background characteristics, for example tumor diameter $(6.13 \pm 2.06 \mathrm{~cm}$ in the laparoscopy group vs. $8.67 \pm 4.38 \mathrm{~cm}$ in the open surgery group). On the other hand, our study population showed similar background characteristics, especially in tumor number $(p=0.778)$ and size $(p=0.769)$, as well as the surgical extent $(p=0.101)$.

In some aspects, laparoscopic surgery was more advantageous than open surgery in our study. Patients who underwent laparoscopic surgery showed less estimated

Table 4. Characteristics of patients who underwent trisectionectomy for liver cavernous hemangioma

\begin{tabular}{lc}
\hline \multicolumn{1}{c}{ Variables } & $\begin{array}{c}\text { Number or mean } \\
\text { (median) }\end{array}$ \\
\hline Sex (Female/male) & $8 / 0$ \\
Mean age (years) & $54.3 \pm 11.3$ \\
Mean BMI & $23.5 \pm 3.5$ \\
ASA 1/2/3 & $3 / 5 / 0$ \\
Median tumor size (range) & $15.75(8-35)$ \\
Site of tumor & \\
Right & $4(50.0 \%)$ \\
Both & $2(25.0 \%)$ \\
Left & $2(25.0 \%)$ \\
Operative data & \\
Operation time, median & $465(211-607)$ \\
EBL, median & $900(150-3200)$ \\
Transfusion (\%) & $4(50.0 \%)$ \\
Postoperative data & \\
Hospital stay, median & $21(8-74)$ \\
Soft diet, median & $4(2-5)$ \\
Removal of drain, median & $13.5(7-74)$ \\
Amount of additional opioid, median & $3(1-15)$ \\
Day for additional opioid, median & $3(1-12)$ \\
Complications & $6(75.0 \%)$ \\
Clavien-Dindo Classification & \\
II & $2(25.0 \%)$ \\
IIIa & $1(12.5 \%)$ \\
IIIb & $3(37.5 \%)$ \\
\hline
\end{tabular}


blood loss, shorter hospital stay, earlier start of soft food diet and less demands of pain control. That is probably because laparoscopic surgery made smaller wound and was less invasive than open surgery.

In our study, the operation time was statistically similar between two groups $(p=0.058)$ in contrast with longer operation time for laparoscopic surgery in previous studies. $^{2-4,7}$ This difference is thought to be related to skill of surgeons who conducted laparoscopic liver resection. Laparoscopic liver resection is a relatively recent procedure which began in the early 1990s. Therefore, as the running curve of surgeons progresses, the surgeon's operation time may become shorter.

Regarding liver resection, $\mathrm{LCH}$ has some unique characteristics compared to other liver tumors. Most patients with $\mathrm{LCH}$ have an otherwise healthy liver with no fibrosis or cirrhosis, while patients with hepatocellular carcinoma have a cirrhotic liver that needs a restricted approach during resection. Pulvirenti et al. ${ }^{20}$ suggested spontaneous or traumatic rupture being most likely in patient with giant hemangioma where the diameter is greater than $10 \mathrm{~cm}$, presence of progressive abdominal symptoms such as pain, satiety or constipation and Kasabach-Merritt syndrome as surgical indications for hepatic hemangioma. There was no rupture nor Kasabach-Merritt syndrome in our study. In our study the reason for laparoscopic surgery was primarily an increase in size whereas the reason for open surgery was symptoms.

Most patients undergo surgery when the tumor is quite enlarged. Because of the large tumor size and the extent of resection, this can lead to a high risk of bleeding and difficulties in performing minimally invasive surgery, which may result in the relatively low use of laparoscopy compared to other liver resections. The observation that laparoscopic trisectionectomy was never performed for LCH in our center during study period implies that laparoscopic resection of a large $\mathrm{LCH}$ is more difficult than smaller one for manipulating a large $\mathrm{LCH}$ is associated with large incisions that are made while extracting the liver. For some cases with a large $\mathrm{LCH}$, one tip which is suctioning the blood within the tumor before extracting the resected liver to minimize the volume of the specimen was useful. This procedure can be also helpful for reducing scarring and increasing the benefits of laparoscopy. Nevertheless, a key issue for laparoscopy is the ma- nipulation and resection of $\mathrm{LCH}$, and therefore it is important to choose cases that are suitable for laparoscopy. As described above, in our study there was a tendency to perform laparoscopy for tumors on the left side. When a large LCH is located on the right side of the liver, the resection plane must be placed on the far-left side since retracting the right liver toward the right side is limited. However, a resection plane for an $\mathrm{LCH}$ on the left side can be placed in the middle since there is more free space available on the left side of the abdomen. Laparoscopy should be considered on a case-by-case basis, and the patient position and port placement should be adjusted for individual cases.

Although one of the surgical indications in our study was possibility of malignancy, the pathologic results of all patients were benign hemangioma. Therefore, there can be ethical arguments about performing unnecessary surgery for LCH. In our study there was no mortality and complication rates were $9.3 \%$ and $12.1 \%$ for laparoscopic and open each. As described before three patients needed intervention such as percutaneous drainage and re-operation due to complications. As a result, patient's informed consent before surgery should be emphasized. In our study all the patients were fully informed at outpatient clinic or ward before surgery about crucial information such as purposes of surgery, other treatment options and possibility of complications then finally agreed to proceed operation.

There are several limitations in our study. First, since this is a retrospective study with a small number of patients, it was impossible to match patients with the same background characteristics. Since we excluded patients who had trisectionectomies, the small number of patients limited propensity score matching. Second, the location of tumor may have influenced the surgeon's decision of surgical procedure and may have caused selection bias. Actually, in our study, patients who had tumor on their right side tended to underwent open surgeries for reasons of surgical technique and resection size. Finally, our judgment of symptoms before and after surgery was entirely relied on medical records at the time of hospitalization or outpatient clinic visits. However, in many cases, the description of patient's symptoms was insufficient or ambiguous. Therefore, the symptoms of some patients might have been ignored or missed. Therefore, we think 
every surgeon should have a virtue of more objective and detailed description of the postoperative patient's symptoms and that would be a great help to future research.

In conclusion, with the exception of cases requiring trisectionectomy, our study showed that laparoscopic resection in patients who have liver cavernous hemangioma was as safe and feasible as open resection (laparotomy) and rather superior in term of less blood loss, less postoperative hospital stay and recovery. However, liver resection for cavernous hemangioma should be conducted after informed consents from patients in consideration of ethical issues.

\section{CONFLICT OF INTEREST}

No potential conflict of interest relevant to this article was reported.

\section{ORCID}

Younghuen Shin: https://orcid.org0000-0001-5252-2546

Jinsoo Rhu: https://orcid.org/0000-0001-9809-8525

Gyu-Seong Choi: https://orcid.org/0000-0003-2545-3105

Jong Man Kim: https://orcid.org/0000-0002-1903-8354

Jae-Won Joh: https://orcid.org/0000-0003-1732-6210

Choon Hyuck David Kwon:

https://orcid.org/0000-0002-1082-3321

\section{AUTHOR CONTRIBUTIONS}

Conceptualization: YS. Data curation: YS, JR, GSC, JMK, JWJ, CHDK. Formal analysis: YS, JR, GSC, JMK. Project administration: YS, JWJ. Visualization: YS, JR. Writing - original draft: YS. Writing - review \& editing: YS, GSC.

\section{REFERENCES}

1. Cho CW, Rhu J, Kwon CHD, Choi GS, Kim JM, Joh JW, et al. Short-term outcomes of totally laparoscopic central hepatectomy and right anterior sectionectomy for centrally located tumors: a case-matched study with propensity score matching. World J Surg 2017;41:2838-2846.

2. Rhu J, Kim SJ, Choi GS, Kim JM, Joh JW, Kwon CHD. Laparoscopic versus open right posterior sectionectomy for hepatocellular carcinoma in a high-volume center: a propensity score matched analysis. World J Surg 2018;42:2930-2937.

3. Wakabayashi G. What has changed after the Morioka consensus conference 2014 on laparoscopic liver resection? Hepatobiliary Surg Nutr 2016;5:281-289.

4. Wakabayashi G, Cherqui D, Geller DA, Buell JF, Kaneko H, Han HS, et al. Recommendations for laparoscopic liver resection: a report from the second international consensus conference held in Morioka. Ann Surg 2015;261:619-629.

5. Jung KU, Kim HC, Cho YB, Kwon CH, Yun SH, Heo JS, et al. Outcomes of simultaneous laparoscopic colorectal and hepatic resection for patients with colorectal cancers: a comparative study. J Laparoendosc Adv Surg Tech A 2014;24:229-235.

6. Suh KS, Hong SK, Lee KW, Yi NJ, Kim HS, Ahn SW, et al. Pure laparoscopic living donor hepatectomy: focus on 55 donors undergoing right hepatectomy. Am J Transplant 2018;18:434-443.

7. Soubrane O, Goumard C, Laurent A, Tranchart H, Truant S, Gayet B, et al. Laparoscopic resection of hepatocellular carcinoma: a French survey in 351 patients. HPB (Oxford) 2014;16:357-365.

8. Tranchart H, Di Giuro G, Lainas P, Roudie J, Agostini H, Franco $\mathrm{D}$, et al. Laparoscopic resection for hepatocellular carcinoma: a matched-pair comparative study. Surg Endosc 2010;24:1170-1176.

9. Yoon YI, Kim KH, Kang SH, Kim WJ, Shin MH, Lee SK, et al. Pure laparoscopic versus open right hepatectomy for hepatocellular carcinoma in patients with cirrhosis: a propensity score matched analysis. Ann Surg 2017;265:856-863.

10. Brouwers MA, Peeters PM, de Jong KP, Haagsma EB, Klompmaker IJ, Bijleveld CM, et al. Surgical treatment of giant haemangioma of the liver. Br J Surg 1997;84:314-316.

11. van Malenstein H, Maleux G, Monbaliu D, Verslype C, Komuta $\mathrm{M}$, Roskams T, et al. Giant liver hemangioma: the role of female sex hormones and treatment. Eur J Gastroenterol Hepatol 2011;23:438-443.

12. Kim IS, Kwon CH. Feasibility of laparoscopic liver resection for giant hemangioma of greater than $6 \mathrm{~cm}$ in diameter. Korean $\mathrm{J}$ Hepatobiliary Pancreat Surg 2014;18:118-121.

13. Bai DS, Chen P, Qian JJ, Yao J, Jin SJ, Wang XD, et al. Modified laparoscopic hepatectomy for hepatic hemangioma. Surg Endosc 2015;29:3414-3421.

14. Giulianotti PC, Addeo P, Bianco FM. Robotic right hepatectomy for giant hemangioma in a Jehovah's Witness. J Hepatobiliary Pancreat Sci 2011;18:112-118.

15. Yu HB, Dong YD, Wang LC, Tian GJ, Mu SM, Cao Y, et al. Laparoscopic versus open resection for liver cavernous hemangioma: a single center of 2-year experience. Surg Laparosc Endosc Percutan Tech 2015;25:e145-e147.

16. Ji J, Gao J, Zhao L, Tu J, Song J, Sun W. Computed tomography-guided radiofrequency ablation following transcatheter arterial embolization in treatment of large hepatic hemangiomas. Medicine (Baltimore) 2016;95:e3402.

17. Gao J, Ding X, Ke S, Xin Z, Ning C, Sha Q, et al. Radiofrequency ablation in the treatment of large hepatic hemangiomas: a comparison of multitined and internally cooled electrodes. J Clin Gastroenterol 2014;48:540-547.

18. Liu L, Li N. Feasibility and advantages of large liver hemangioma treated with laparoscopic microwave ablation. Hepatogastroenterology 2014;61:1068-1073.

19. Clavien PA, Barkun J, de Oliveira ML, Vauthey JN, Dindo D, Schulick RD, et al. The Clavien-Dindo classification of surgical complications: five-year experience. Ann Surg 2009;250:187-196.

20. Pulvirenti E, Toro A, Di Carlo I. An update on indications for treatment of solid hepatic neoplasms in noncirrhotic liver. Future Oncol 2010;6:1243-1250. 